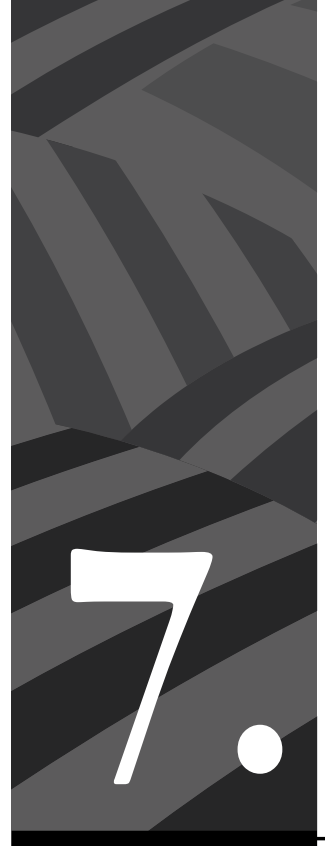

Luchas de las mujeres excombatientes de las FARC-EP por la reproducción de la vida colectiva en Pondores

y Tierra Grata 


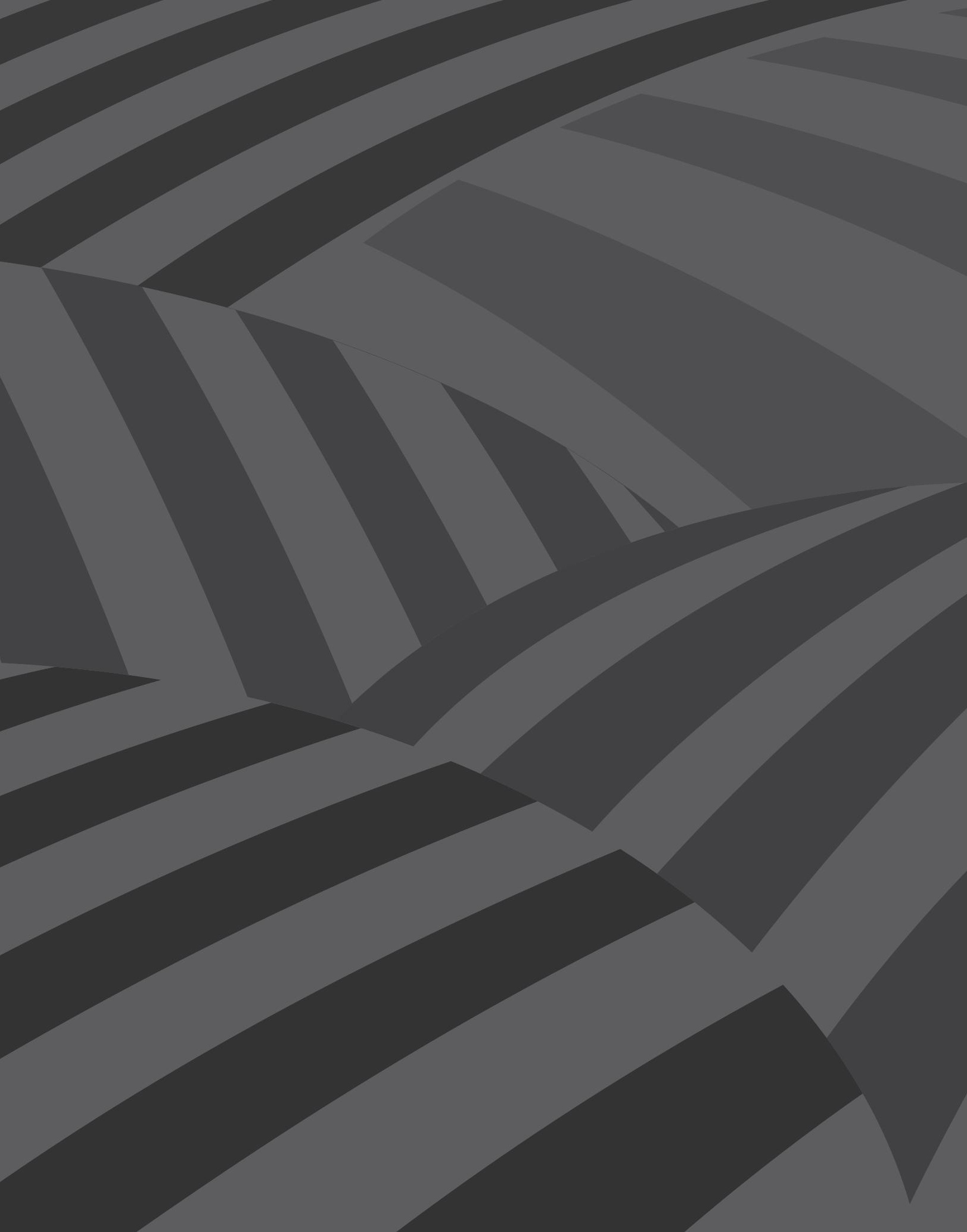




\section{Luchas de las mujeres excombatientes de las Farc-EP por la reproducción de la vida colectiva en Pondores y Tierra Grata}

Por Diana Patricia González Ferreira*

DOI: https://doi.org/10.54118/controver.vi217.1240

Resumen: Este artículo analiza la implementación del proceso de reincorporación de los y las excombatientes de las Fuerzas Armadas Revolucionarias de Colombia-Ejército del Pueblo (FARC$\mathrm{EP}$ ) en los antiguos espacios territoriales de capacitación y reincorporación (ETCR) de Pondores y Tierra Grata en el caribe colombiano. Para ello, en el texto se examina el incumplimiento de los acuerdos, los obstáculos que los y las excombatientes junto con sus familias deben enfrentar cada día, y las estrategias que las exguerrilleras adoptan en su lucha por la producción de común y la reproducción material y simbólica de la vida colectiva.

Palabras clave: reincorporación, mujeres excombatientes, reproducción de la vida colectiva, producción de común.

\section{Farc-EP Female Former Fighters' Struggle for the Reproduction of Collective Life in Pondores and Tierra Grata}

Abstract: This article analyzes the implementation of the reincorporation process of ex-combatants of the Revolutionary Armed Forces of Colombia-People's Army (FA $<<$ RC-EP) in the former Territorial Spaces for Training and Reincorporation (ETCR) of Pondores and Tierra Grata in the Caribbean region of Colombia. For this, in the text, examines the failure to implement the contents of the agreement, the obstacles that the ex-combatants and their families face in their territories, and the strategies that ex-guerrilla women use in their everyday life struggle to produce the commons as well as the material and symbolic reproduction of collective life.

Keywords: Reincorporation, Women ex-combatants, reproduction of collective life, Production of common.

* Licenciada en Psicología y Pedagogía. Maestría en Sociología, del Instituto de Ciencias Sociales y Humanidades “Alfonso Vélez Pliego” de la Benemérita Universidad Autónoma de Puebla, Mexico. Correo electrónico: dipagonfe@gmail.com 
Cómo citar este artículo: González Ferreira, Diana Patricia (2021). Luchas de las mujeres excombatientes de las Farc-EP por la reproducción de la vida colectiva en Pondores y Tierra Grata. Revista Controversia, 217, 257-298.

Fecha de recepción: 28 de febrero de 2021

Fecha de aprobación: 14 de abril de 2021

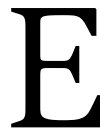

ste texto se nutre de las reflexiones realizadas en la tesis del mismo título, llevada a cabo en la Maestría en Sociología del Instituto de Ciencias Sociales y Humanidades "Alfonso Vélez Pliego", de la Benemérita Universidad Autónoma de Puebla-México. En ambos trabajos las mujeres excombatientes, sus luchas por la reproducción de la vida y la producción de común están al centro, vistas a la luz de sus experiencias en dos antiguos espacios territoriales de capacitación y reincorporación (ETCR) ${ }^{1}$ de la región Caribe.

Así, lo que me propongo aquí es exponer la forma en que el Acuerdo final para la terminación del conflicto y la construcción de una paz estable y duradera (en adelante Acuerdo), suscrito en 2016 entre el Gobierno colombiano y las Fuerzas Armadas Revolucionarias de ColombiaEjército del Pueblo (FARC-EP), ha generado condiciones precarias para las excombatientes que dejaron las armas en pos de una sociedad más justa. Los incumplimientos del Estado colombiano y la lenta implementación de lo pactado han llevado a los y las excombatientes a un laberinto burocrático sostenido en medidas provisionales, que alejan las posibilidades de una reincorporación real y de cumplir el sueño de construir una paz estable y duradera. A pesar de esto, las mujeres excombatientes de las FARC-EP, dentro de los espacios de reincorporación

1 Los ETCR fueron una figura jurídica transitoria creada para la reincorporación temprana de las y los excombatientes. En principio tendrían vigencia desde el 15 de agosto del 2017 hasta el 15 de agosto del 2019, tiempo en que no se cumplió con el objetivo trazado, por lo cual fue ampliada por un año más, es decir, hasta el 15 de agosto del 2020, lo que significa que a la fecha no existe certeza jurídica sobre estos espacios. 
colectivos, siguen luchando por producir común y garantizar la reproducción de la vida de forma colectiva.

El texto se divide en dos partes: en la primera describo de forma general el problema de la tierra como causa estructural del conflicto armado colombiano y el proceso de paz, resaltando algunas características particulares de estos dos elementos en torno a las mujeres; en la segunda, centrada en las mujeres excombatientes de los antiguos ETCR de Pondores y Tierra Grata, expongo, desde una perspectiva antipatriarcal, algunos elementos del contexto particular de la región donde se encuentran estos territorios, así como las condiciones materiales y simbólicas, las dificultades y las estrategias que despliegan ellas en su lucha cotidiana para reproducir la vida en comunidad.

\section{La tierra, un problema estructural}

La cuestión agraria, especialmente el acceso y uso de la tierra, "es un tema sobre el cual existe consenso entre quienes han investigado el proceso, como 'factor desencadenante' del conflicto social y armado" (Fajardo, 2015, p. 6). Los "despojos múltiples" (Navarro Trujillo, 2015) de los medios de subsistencia (tierra, agua, bosques, entre otros) de comunidades indígenas, afrodescendientes y campesinas han concentrado la tierra en manos de unos pocos, en detrimento de las mayorías. Este ha sido el factor central de una larga historia de luchas dentro del campo colombiano y de un continuum de violencia que prevalece hasta la actualidad.

La estrecha relación entre el poder político y los perpetradores de este despojo ha sido un elemento importante en estos procesos de concentración de la tierra. Investigaciones como las de Aponte (2019), Fals Borda (2008), Legrand (2016) y Vega Cantor (2002) muestran cómo el control territorial ha estado vinculado históricamente con el poder político, las dinámicas electorales, la empresas extractivistas y el Estado. En este sentido, el largo conflicto en Colombia ha sido una sucesión de luchas en torno a la tierra. 
Con una desigualdad profundamente violenta, el acaparamiento de tierras muestra cifras de una realidad absurda. El último censo nacional agropecuario (DANE, 2014) revela que, de las 111.5 millones de hectáreas en área continental colombiana, el $56.7 \%$ son bosques (63.2 millones de ha) y el $38.6 \%$ son aptas para uso agropecuario (43.1 millones de ha). Sin embargo, solo 8.5 millones de hectáreas están destinadas a siembra de cultivos, es decir, únicamente el $7.1 \%$ de la tierra con vocación agrícola tiene uso efectivo. De las 34.4 millones de hectáreas restantes, el $80 \%$ están dedicadas a la ganadería.

Según el Oxford Committee for Famine Relief (Oxfam, 2017), la diferencia entre la superficie apta para la ganadería -15 millones de ha- y la que ocupa realmente -34.4 millones de ha- deja un excedente de 19.4 millones de hectáreas de ganadería que podrían ser destinadas para otros usos. La situación es aún más inadmisible cuando se estima que una cabeza de ganado en Colombia tiene en promedio 1.6 ha a su disposición, mientras que "un millón de explotaciones campesinas tienen un tamaño inferior al que dispone en promedio una vaca en Colombia” (Oxfam, 2017, p. 23). Al hablar de explotación se hace referencia a la tierra que efectivamente puede ser cultivada, explotada.

Del total de explotaciones registradas hasta 2014, aquellas mayores a 500 ha representan del $0.4 \%$ al $0.5 \%$. No obstante, aunque se ha mantenido su porcentaje, la cantidad de hectáreas que las componen ha crecido exponencialmente desde 1960 hasta 2014, pasando de 5 millones de hectáreas en promedio a 47 millones. En síntesis, “el 1\% de las explotaciones de mayor tamaño maneja más de $80 \%$ de la tierra, mientras que el $99 \%$ restante se reparten menos del $20 \%$ de la tierra” (Oxfam, 2017, p. 13). Siendo así, no extraña que Colombia haya sido calificada, según el coeficiente de Gini calculado por Oxfam, como el país más desigual de la región, seguido por Perú y Chile. 
La condición de las mujeres es aún peor. Sin datos suficientes ${ }^{2}$ para conocer el estado real de la situación ${ }^{3}$, se estima que su acceso a maquinaria, créditos y asistencia técnica, así como a la tierra, es menor. Además, según Deere y Leon, existen factores que propician la brecha de inequidad entre mujeres y hombres en relación con la propiedad de la tierra, como la "preferencia masculina en la herencia, el privilegio del que goza el hombre en el matrimonio, el sesgo hacia el sexo masculino tanto en programas comunitarios y estatales sobre reparto de tierras como en el mercado de tierras, en donde la mujer pocas veces es participante exitosa como compradora" (2005, p. 3).

Anudado a esto se encuentra el desempleo rural, que en el caso de las mujeres es de un $9.7 \%$, frente a un $2.3 \%$ de los hombres (Comisión Colombiana de Juristas, 2011). También se debe tener en cuenta que ellas realizan gran parte de las labores de cuidado que garantizan la reproducción de la vida familiar y comunitaria, sin que esto les represente algún tipo de ingreso o remuneración.

La falta de titulación de la tierra a nombre de las mujeres, en medio de un conflicto armado que ha dejado más de 7 millones de desplazados, las mantiene en lugares de vulnerabilidad y dependencia históricas. El asesinato, la desaparición, el abandono y desplazamiento de los varones, sumado a la informalidad en la tenencia de la tierra, entre otros

2 Para un análisis de los problemas en la construcción de datos sobre el acceso y tenencia de tierra por parte de las mujeres, véase: "La desigualdad de género en la propiedad de la tierra en América Latina” (León, 2011).

3 El último censo agropecuario en Colombia se realizó en el 2014, por lo cual no existen datos actualizados y discriminados que reflejen la situación de la población rural en general y de las mujeres en particular. En este sentido, el Acuerdo de Paz en el numeral 1.1.9 consagró la "formación y actualización del catastro e impuesto predial rural", para lo cual el Gobierno Nacional pondrá en marcha: un Sistema General de Información Catastral, integral y multipropósito, que en un plazo máximo de 7 años concrete la información y actualización del catastro rural" (Gobierno Nacional y FARC-EP, 2016). 
aspectos, dejan a las mujeres y sus familias frente al despojo, y con la imposibilidad de acceder a derechos de restitución de tierras o titulación. Vemos entonces cómo el continuum de violencia, que se exacerba en la guerra, es experimentado por las mujeres de forma particular y no es ajeno a la realidad que actualmente atraviesan quienes se acogieron al Acuerdo, como veremos más adelante.

Con todo y esto, las mujeres no han cesado en la lucha por la tierra, los bienes comunes y una vida digna. Ellas han trabajado hombro a hombro con sus compañeros y organizaciones para defender sus territorios y conseguir tierra para quien la trabaje. A pesar de la poca relevancia histórica que se ha dado al hacer (Holloway, 2011) de las mujeres dentro de las luchas campesinas, indígenas y afrodescendientes en torno a la tierra, es innegable que ellas son parte fundamental en estos procesos ${ }^{4}$. Es por esto que frente a la posibilidad de un acuerdo de paz las mujeres buscaron ser parte de este, viendo allí una oportunidad de transformación social que avivaba la esperanza de construir una sociedad más justa.

\section{El Acuerdo de Paz y las mujeres}

El Acuerdo de Paz firmado en Colombia es el primero en el mundo en incluir el enfoque de género de forma trasversal, con lo cual se posicionó como el más avanzado en el reconocimiento de los derechos de las mujeres y la población LGTBI. Este logro es fruto del trabajo de las mujeres, quienes desde el inicio de las conversaciones en La Habana buscaron y construyeron estrategias para interlocutar e interpelar a la Mesa de Diálogo y a sus negociadores. Con sus organizaciones, el impulso de las mujeres farianas, el apoyo de los países garantes y la cooperación internacional, lograron crear la Subcomisión de Género, desde la cual se construiría la perspectiva de género del Acuerdo Final.

4 Para un análisis sobre la exclusión de la experiencia de las mujeres en las luchas por la tierra, véase el primer capítulo de la tesis Las luchas de las mujeres excombatientes por la reproducción de la vida en Pondores y Tierra Grata, en repositorio BUAP. 
Tres caminos se juntaron en este proceso: uno, el de las organizaciones de mujeres y su larga lucha por lograr una salida negociada al conflicto armado; dos, el de las mujeres farianas, quienes vieron la necesidad de reconstruir su legado histórico dentro de la organización y comenzaron a tener acercamientos formativos sobre feminismos y género; tres, el de las luchas de feministas y de mujeres a nivel internacional, que han incidido en los organismos multilaterales y llevado a que la ONU promulgara, entre otras, la Resolución 1325 del Consejo de Seguridad de las Naciones Unidas (2000), donde se insta a los Estados a incluir la participación activa de las mujeres en los procesos de paz y los posacuerdos.

Los recorridos de estos caminos son muestra de la pluralidad de luchas de las mujeres, feministas o no, las cuales a pesar de sus diferencias se encontraron en La Habana para poner en juego sus apuestas y propuestas frente a la reconstrucción de una sociedad que busca ir en dirección contraria a la trazada por la guerra. Sin embargo, en la actualidad y tras cinco años de firmado el Acuerdo, la situación de las mujeres excombatientes y sus comunidades es compleja. Pese a los grandes esfuerzos para construir un Acuerdo de Paz que lograra transformaciones profundas, donde las mujeres tuvieran un lugar significativo, la realidad dista mucho de ser lo que se esperaba.

Según los informes de la Secretaría Técnica del Componente Internacional de Verificación CineP/PPP-CERAC (2019) y el Instituto Kroc (2019), la implementación del Acuerdo de Paz ha sido lenta. Esto se refleja de manera contundente en los puntos 1: Reforma Rural Integral y 4: Solución al problema de las drogas ilícitas, donde "hubo pocos avances en materia de acceso y uso de la tierra” (CINEP/PPP-CERAC, 2019, p. 4), dos aspectos fundamentales que dieron origen al levantamiento armado de las FARC-EP en 1964.

Además, según datos del Instituto Kroc (2019), estos dos temas centrales del Acuerdo de Paz son los más rezagados. Los porcentajes de 
cumplimiento para estos puntos son respectivamente: avance completo $3 \%$ y $2 \%$; avance mínimo $51 \%$ y $50 \%$; no se ha iniciado ningún avance $37 \%$ y $30 \%$. Lo que significa, en términos concretos, que no se han llevado a cabo las acciones legislativas, políticas y técnicas para su desarrollo, afectando significativamente a las mujeres, quienes se verían beneficiadas del enfoque de género.

Es por ello que resulta importante hacer un acercamiento a las condiciones materiales y simbólicas que atraviesan actualmente las mujeres excombatientes ubicadas en los antiguos ETCR de Pondores y Tierra Grata, pues desde allí se pueden evidenciar las profundas contradicciones del Gobierno al comprometerse a cumplir con los puntos del Acuerdo de Paz, mientras, a su vez, construye toda una arquitectura burocrática que impide su efectivo desarrollo. Así mismo, conocer aquello que sucede en estos territorios nos permite, de forma situada y parcial (Haraway y Brass, 2014), ver el despliegue de la potencia transformadora de las mujeres excombatientes que cotidianamente luchan producir las condiciones necesarias para una vida digna.

\section{Para entrar al contexto de la región}

La Guajira y el Cesar son territorios fronterizos que tienen una amplia y diversa presencia indígena, campesina y afrodescendiente. Sin embargo, la falta de acceso a la tierra, al agua y demás bienes comunes para la reproducción de la vida humana ha atravesado la historia de estos departamentos. Las violencias y los despojos por parte de terratenientes $^{5}$, empresas mineras y palmeras, que se han afirmado en el territorio con la complicidad del Estado y su aparato militar y paramilitar, han marcado a los ecosistemas y a las comunidades. El conflicto armado y la persecución a las organizaciones campesinas, indígenas y obreras

5 El uso exclusivo del masculino en terratenientes busca evidenciar que históricamente han sido los varones los principales expropiadores y acaparadores de tierra. 
que se dio en las décadas de los ochenta y noventa, revelan una zona de múltiples conflictos. Sin embargo, y a pesar de las lógicas coloniales, patriarcales y capitalistas que han intentado imponerse en el territorio, la fuerza y organización de las tramas comunitarias, desde diferentes espacios, se siguen resistiendo a estas formas de dominación.

En la actualidad, la configuración del capital en La Guajira se centra en la extracción del carbón. En el extremo nororiental del departamento se encuentra El Cerrejón, una de las minas de carbón a cielo abierto más grandes del planeta, que desde 1975 realiza labores de explotación en la cuenca del río Ranchería, la Sierra Nevada de Santa Marta y la Serranía del Perijá. La extracción del carbón ha generado afectaciones al territorio y sus comunidades, entre ellas la contaminación y sequía de las fuentes hídricas, desplazamientos forzosos y conflictos territoriales.

"Según Ingeominas, la región de La Guajira y el César son los departamentos con mayor reserva carbonífera, pudiendo suplir las necesidades del mercado mundial hasta unos cien años dependiendo de las exigencias del mercado” (Forero, Matos y Amador, 2017, párr. 10). De la explotación minera del Caribe se generan los ingresos económicos más altos del país en este sector: del 15\% al 20\% de PIB minero (Agencia Nacional de Minería, 2020). A la vez, esta misma región presenta uno de los índices de pobreza más altos a nivel nacional, solo superados por el departamento de Chocó, que tiene el mayor número de necesidades básicas insatisfechas del país (Defensoría del Pueblo, 2014).

Por su parte, el Cesar ha estado atravesado por flujos de capital legales e ilegales en los que pocas veces es posible establecer los límites entre uno y otro. La bonanza marimbera en los setenta y ochenta, y la consolidación a sangre y fuego de los paramilitares en los noventa, que abrieron paso a la explotación minera, al monocultivo extensivo de palma africana y a la ampliación de tierras ganaderas, marcan una sucesión de 
violencias organizadas en torno a la propiedad y uso de la tierra para la minería, la agroindustria y la ganadería ${ }^{6}$.

En la actualidad, Fedepalma y Cenipalma asocian nueve núcleos palmeros en 23 de los 25 municipios del departamento, con más de 80 000 hectáreas sembradas, y cada hectárea necesita aproximadamente 42000 litros de agua. Empresas mineras de carbón como Drummond, Prodeco, Munrray Energy y Glencore hacen presencia en la zona, con una producción anual que supera los 50 millones de toneladas.

En el caso del carbón, sus principales explotadores son la estadounidense Drummond y la suiza Glencore, las cuales operan en Colombia desde 1986 y 1995 respectivamente. Según el Informe sombra de sostenibilidad de las operaciones de Glencore en Colombia (PAS y ASK, 2015) y el documento Minería de carbón - Drummond - Prodeco - Murray Energy - Cesar. Análisis Dinámica de Actores y Acciones, del Observatorio de Conflictos Ambientales y el Instituto de Estudios Ambientales de la Universidad Nacional de Colombia (2017), estas empresas han establecido alianzas tanto con los grupos armados, guerrillas y paramilitares como con el Ejército Nacional. Esta unión ha sido parte de sus estrategias para garantizar el control de todos los factores (población, agua, tierra) asociados con su actividad extractiva.

No obstante, el Caribe posee una fuerte historia de luchas y resistencias indígenas, campesinas, afrodescendientes y obreras. En la década de los ochenta el despliegue de movilizaciones masivas hacia Valledupar, capital del Cesar, logró sacudir la región y llamar la atención del Estado frente a las condiciones precarias en las que estaban sumidas las comunidades. Ante esto, la arremetida contra la organización social fue

6 Sobre una reconstrucción de la memoria histórica reciente del departamento del Cesar, véase Campesinos de tierra y agua. Memorias sobre sujeto colectivo, trayectoria organizativa, daño y expectativas de reparación colectiva en la región Caribe 1960-2015 (Centro Nacional de Memoria Histórica, 2017). 
terrorífica no solo en el Caribe, sino en todo el territorio colombiano (CNMH, 2017). Con la apertura económica en los noventa y el giro hacia la extracción de materias primas como el carbón, la región pasó a ocupar un lugar importante para los intereses económicos del país, por las amplias reservas minerales en la zona.

Un territorio donde los repertorios de violencia y control territorial buscan constituir un orden social contrainsurgente por parte del Estado y el paramilitarismo, deja su impronta en la subjetividad de quienes habitan allí. Con una pedagogía de la crueldad que se escribe en los cuerpos feminizados y de las mujeres se tiende a romper la empatía por los otros y a normalizar la violencia (Segato, 2018).

\section{Un acercamiento a los espacios territoriales de capacitación y reincorporación}

En esta región se encuentran los antiguos ETCR de Pondores (La Guajira) y Tierra Grata (Cesar). Allí, en el 2016, llegaron 398 hombres y mujeres pertenecientes a los frentes 19, 41 y 59 de las FARC-EP que operaban en los departamentos de La Guajira, Magdalena y Cesar. En la actualidad, en estos ETCR se está desarrollando de forma colectiva parte de lo que en el Acuerdo se estableció como:

La reincorporación a la vida civil será un proceso de carácter integral y sostenible, excepcional y transitorio, que considerará los intereses de la comunidad de las FARC-EP en proceso de reincorporación, de sus integrantes y sus familias, orientado al fortalecimiento del tejido social en los territorios, a la convivencia y la reconciliación entre quienes los habitan; así mismos, al despliegue y el desarrollo de la actividad productiva y de la democracia local. (Gobierno Nacional y FARC-EP, 2016, pp. 68-69).

Sin embargo, y a pesar del compromiso que adquirió el Estado colombiano con las FARC-EP y la sociedad en general con la firma del 
Acuerdo, los incumplimientos han sido evidentes y reiterativos desde el principio, incluso antes de la dejación de armas en el 2016, y hasta la actualidad. Una mirada a los ETCR de Pondores y Tierra Grata, y a sus condiciones materiales, evidencia la precaria visión en la construcción de estos y la falta de garantías para la reincorporación integral de las y los excombatientes.

A pesar de esto, las comunidades han sido quienes han buscado estrategias para conseguir agua, energía y vivienda, produciendo los bienes materiales y simbólicos que les permitan, en un futuro, habitar con dignidad el territorio. En este sentido, es interesante ver cómo la producción de común y la reproducción de la vida ayudan a avanzar en la comprensión de aquello que sucede en estos espacios. Siguiendo el planteamiento de Gutiérrez, Linsalata y Navarro:

Lo común se produce, se hace entre muchos, a través de la generación y constante reproducción de una multiplicidad de tramas asociativas y relaciones sociales de colaboración que habilitan continua y constantemente la producción y el disfrute de una gran cantidad de bienes -materiales e inmateriales- de uso común. (2016, pp. 7-8).

Desde esta perspectiva, entendemos que "lo común" no es "algo" sino, más bien, las relaciones sociales que lo producen. Se trata de acciones dinámicas como un proceso continuo y de ninguna manera un producto final. Así, en la medida que se generan las condiciones materiales para la vida, se tejen las relaciones sociales que se requieren para su sostenimiento. De ahí que la vida, a la vez que se transforma, se conserva en el hacer cotidiano.

En este sentido, las mujeres excombatientes se enfrentan a una nueva realidad en la que su vida cotidiana se ha transformado radicalmente. Aun así, su mundo de significados y tramas comunitarias, ligadas a su tradición de lucha guerrillera, las acompaña en un tiempo donde actualizan sus luchas. 
Aquí es una lucha muy diferente, porque ya es una lucha política, una lucha social, una lucha por mantenernos organizados; es una lucha empezando desde que nos levantamos hasta que nos acostamos por todo lo que nos rodea; la lucha por el agua, la lucha por la sana convivencia, la lucha porque haya unos derechos para las personas, por el respeto. (Rubiela, comunicación personal, 12 de julio de 2019).

Así pues, el cambio de las formas de lucha de las mujeres farianas son continuos ensayos en la vida cotidiana, que podrían prefigurar caminos posibles hacia la transformación social. Con todo, las contradicciones, tensiones e incertidumbres a las que se enfrentan, también muestran una realidad compleja que rompe con el romanticismo revolucionario.

\section{Reproducción material de la vida en los ETCR de Pondores y Tierra Grata}

La reincorporación de las FARC-EP a la vida civil tiene dos componentes: uno social y económico, y otro político. En cuanto al primer componente, el Estado otorga a las y los excombatientes una manutención que consiste en un ingreso del $90 \%$ de un salario mínimo legal en Colombia cada mes -alrededor de 207 dólares-, más un abastecimiento mensual de víveres. Así mismo, al finalizar las zonas veredales transitorias de normalización (ZVTN) ${ }^{7}$ se le entregó a cada excombatiente una asignación económica inicial y única de alrededor de 592 dólares. Además, cuentan con un apoyo económico de 2324 dólares destinados a proyectos productivos, que podrán desarrollarse en cooperativas.

En cuanto a lo social, el Estado debe garantizarles acciones y programas en relación con educación, reincorporación de menores de edad, seguridad social por dos años y planes sociales. Estas medidas tienen carácter

7 Así fueron llamados los lugares de preagrupamiento para la dejación de armas, de conformidad con el punto 3 del Acuerdo: Fin del Conflicto. 
transitorio y provisional, es decir, que caducan en el tiempo; de hecho, ya se han hecho modificaciones en este aspecto ${ }^{8}$

En relación con la reincorporación política:

Las FARC-EP se constituirán en un Partido Político Legal que gozará de los derechos y obligaciones propios del orden constitucional vigente. El Gobierno Nacional generará todas las garantías y condiciones para facilitar la creación y funcionamiento de este nuevo Partido (Forjando Paz, 2017, p. 39).

Para ello el Estado otorgó personería jurídica al partido, el cual se conformó en el Congreso Constitutivo del Nuevo Partido realizado entre el 28 y 29 agosto del 2017 en Bogotá. Allí se creó la Fuerza Alternativa Revolucionaria del Común (FARC) ${ }^{9}$ y se definieron sus directrices, entre ellas su carácter antipatriarcal, y en este mismo sentido se estableció la Comisión Nacional Mujer, Género y Diversidad. Desde esta Comisión se han venido realizando distintos trabajos en los antiguos ETCR, para abordar los temas de fortalecimiento de la participación política para mujeres, lucha contra todas las formas de violencia contra las mujeres, nuevas masculinidades o masculinidades no violentas, reconocimiento de la diversidad sexual y transformación de prejuicios contra la comunidad LGTBI.

Desde la Comisión Nacional Mujer, Género y Diversidad se propuso la Estrategia Integral para la Reincorporación de las Mujeres FARC-EP (en adelante Estrategia). En ella se plantea desde dos enfoques, igualdad y derechos, construir un plan de acción para hacer integral y sostenible el proceso de reincorporación de las mujeres farianas de forma colectiva.

8 Aunque la bancarización, es decir el 90\% del salario mínimo que reciben, y el abastecimiento mensual tendrían vigencia solo durante dos años, que era el tiempo esperado para la reincorporación, esta se ha extendido dos veces mediante decreto presidencial, a causa de los retrasos en los trámites y asignación de los proyectos productivos, la continuidad escolar y el nulo avance en cuanto a la reforma rural integral.

9 En la actualidad Partido Comunes. 
El acento que las excombatientes ponen en este punto es relevante, ya que:

Para las FARC la reincorporación con enfoque de género, también implica dar continuidad a las configuraciones de la vida colectiva y comunitaria que por más de cincuenta años se fueron consolidando al interior de la insurgencia; allí los roles tradicionales de género fueron transformados hacia nuevas formas de vivir la feminidad, la masculinidad y su inter relacionamiento en un contexto de igualdad y complementariedad. En consecuencia, el tránsito a la vida civil debe mantener un carácter colectivo, enmarcado en los principios de solidaridad y respeto, en donde el desarrollo de lo subjetivo y el reconocimiento a las particularidades y derechos específicos de las mujeres en su diversidad fortalezcan la reincorporación de las mujeres. Todo ello buscando mantener la unidad del tejido sociocultural de las FARC (Comisión Mujer, Género y Diversidad, 2020, pp. 4-5).

Mantener las dinámicas "paritarias” de cuidado que se tuvieron dentro de la guerrilla es parte de lo que buscan con la Estrategia, teniendo en perspectiva que el enfoque de género no se limite a un "término jurídicamente correcto", sino al efectivo despliegue de capacidades institucionales, técnicas y políticas que impacten de forma positiva la vida de las excombatientes. Al respecto plantean cinco líneas de acción: política, social, económica, sociojurídica y de garantías de seguridad.

En lo político, proyectan cualificar la participación y representación política de las mujeres y la reconstrucción de su memoria histórica ${ }^{10}$ para el reconocimiento de las farianas como sujetas políticas revolucionarias. En lo social, buscan "prevenir y superar los condicionamientos sociales que ubican naturalmente a las mujeres en roles de cuidado

10 Dentro de esta estrategia se plantean "la posibilidad de articular acciones con el Centro de Memoria Histórica (Ley 1448 de 2011) e intervenir en la modificación de los lineamientos curriculares de Ciencias Sociales para que se enseñe historia colombiana (Ley 1874 de 2017)” (Comisión Mujer, Género y Diversidad, 2018). 
limitando su movilidad al ámbito doméstico" (Comisión Mujer, Género y Diversidad, 2018, p. 27). Para ello proponen atención psicosocial colectiva, educación, salud diferenciada para las mujeres, y la prevención y atención para una vida libre de violencias. En lo económico, plantean fortalecer la autonomía económica de las mujeres y promover procesos de transformación de las formas de organización de la reproducción social y la economía del cuidado, esto último perfilando los cuidados como una labor colectiva entre varones y mujeres. En lo sociojurídico la estrategia se centra en la garantía de acceso a la justicia de la JeP; y en relación con la seguridad buscan garantías para las mujeres tanto en la reincorporación a la vida civil como en la participación política.

\section{El 6 × 4: espacios habitacionales}

Las unidades habitacionales donde viven las y los excombatientes en proceso de reincorporación desde el 2016 están hechas en drywall (pared seca), un material prefabricado que se utiliza sobre todo en construcciones internas o de pronta remoción, y que ahorra costos de cemento y agua. Cada pared se conforma de una estructura de acero galvanizado con rieles y parantes, recubiertas con láminas de yeso o cemento blanco. Este sistema se utilizó en todos los ETCR del país (24 en total), sin importar las condiciones climáticas. En los casos de Pondores y Tierra Grata, el calor que se concentra dentro de estas unidades, sobre todo después de mediodía, hace insoportable estar dentro.

En ambos ETCR se cuenta con espacios para enfermería, jardín infantil, recepción, aulas y biblioteca, todos hechos con el mismo material. Sin embargo, esto no significa que tales áreas cuenten con las condiciones, la dotación y el recurso humano necesario para el funcionamiento de dichos servicios. Sin embargo, los y las excombatientes han procurado mantener, de alguna manera, el servicio de enfermería con sus conocimientos y experiencias, a pesar de que los instrumentos necesarios para esta labor son escasos. En cuanto a los jardines infantiles, en Pondores se ha logrado ponerlo en funcionamiento, aliviando la carga de 
las excombatientes, pero en Tierra Grata sigue inhabilitado por temas burocráticos.

En Pondores hay 240 alojamientos, mientras que en Tierra Grata son 158. Si bien a cada excombatiente se le entregó una unidad habitacional, esto no quiere decir que solo ellos y ellas vivan allí. La recomposición familiar y las familias recién constituidas también comparten el espacio con ellas y ellos, lo que hace más compleja la situación.

Hay gente que solo tiene un cuarto y resulta que ese cuarto es un excombatiente, pero su compañera no es excombatiente, es civil, no tiene derecho al otro cuarto, porque fue hecho pa' los excombatientes no más. Y a veces la compañera tiene dos y tres hijos, [...] entonces tiene dos o tres hijos, entonces un hacinamiento, ahí tiene que tener cocina, dormida y cuarto pa los niños, en un espacio de 6 metros por 4 de ancho, la mayoría viven aquí así. (Rubiela, comunicación personal, 12 de julio de 2019).

La organización en cuadrícula de las unidades habitacionales no solo moldea el lugar, sino también las formas de interacción y socialización, imponiendo fronteras físicas y simbólicas que aíslan a cada uno y una en su espacio privado. A la vez, la pérdida de los espacios colectivos que la vida militar les proporcionaba, afecta las capacidades para generar bienestar en aspectos básicos como la salud, que anteriormente se resolvía de forma colectiva, así fuera en condiciones precarias.

El contraste entre habitar una unidad habitacional de forma individual o colectiva cada día va mostrando sus ventajas y desventajas. La familia podría llegar a asumir el cuidado en situaciones de enfermedad, sin embargo, el nivel de hacinamiento e incomodidad que esto implica es evidente. En Tierra Grata, por falta de espacio, algunas personas han organizado cocinas colectivas que se ocupan por turnos, mientras la gran mayoría han adecuado los espacios para poder tener dentro de la unidad su propia cocina, cosa que no se puede hacer con otras partes 
que requiere una casa, como por ejemplo, el lugar para lavar la ropa e incluso el baño y la ducha.

\section{El problema de la tierra vuelve a estar en el centro de la lucha}

Haber pensado estos espacios como algo transitorio (estimado en dos años), para ser habitados por un ejército y con las características de un campamento, hace que realmente los antiguos ETCR no sean lugares aptos para vivir en familia y habitar en el tiempo. Por eso, la prioridad para ellos y ellas ha estado en conseguir la titulación de estos predios o de otros cercanos, para poder construir sus viviendas, ya que la negociación no contempló de forma específica el acceso a tierra y a vivienda digna para las y los excombatientes. Frente a esto, Nayeli dice:

Lo que debieron hacer es, en vez de invertir en esto, poner un poquito más o lo mismo pero que cada uno con su pedazo de tierra y vamos construyendo y organizar su casa a su gusto, cada uno en su propio terreno. (Comunicación personal, 12 de julio de 2019).

Con los ETCR como espacios transitorios y sin una asignación cierta de tierras para excombatientes, el problema de la tierra vuelve a estar en el centro. A pesar de que en la actualidad existe el compromiso por parte del Gobierno de comprar los predios donde se encuentran algunos de los ETCR, a más de tres años de firmado este compromiso aún no se ha avanzado en ello.

Al no ser la tierra de propiedad de los y las excombatientes, los proyectos productivos que requieren de esta para su desarrollo no han sido aprobados. Este asunto no es menor, teniendo en cuenta que en su gran mayoría provienen de tradición campesina. Según Martínez y Lefebvre, el $80.6 \%$ de los proyectos presentados hasta el momento están catalogados como agropecuarios (2019). 
Tanto Pondores como Tierra Grata están en camino de adquirir unos predios cercanos a los ETCR para que los y las excombatientes puedan construir sus casas. Sin embargo, cada uno ha tenido obstáculos en este proceso, que les han impedido hacerlo. En Pondores se espera que con el aporte de la Gobernación de La Guajira, el municipio de Fonseca y la cooperación internacional, más los 2324 dólares del proyecto productivo, logren sacar adelante la compra de tierras y la construcción de sus viviendas.

En los dos casos se han creado cooperativas a las que se asocian quienes están proyectando tener su casa allí e invertir este dinero. Aun así, no se tiene claridad sobre la compra de los terrenos, ni del tiempo que va a tardar su adquisición. A pesar de que esto afecta a toda la comunidad, claramente son las mujeres quienes están buscando desarrollar sus proyectos de vida en el territorio y echar raíces impulsando este proyecto, en el que las dilaciones por parte del Estado son evidentes.

Las mujeres lo que más queremos y hemos pedido es tierra. Todo el proceso lo llevamos acá luchando, pidiéndolo y el gobierno nos ha engañado con la tierra y no nos cumple; el proyecto de vivienda está que se nos funde, la comunidad internacional nos hizo una donación y lo tenemos ahí. El mismo gobierno tiene la obligación de darnos un incentivo de ocho millones [2324 dólares] para proyectos productivos y nosotros lo queremos como vivienda y esta es la hora que no... (Rubiela, comunicación personal, 12 de julio de 2019).

El caso de Tierra Grata es mucho más complejo. Allí no solo han juntado el dinero a través de las cooperativas, sino que adquirieron una deuda con un banco para la compra de tierras, y la están pagando en la actualidad.

De otra parte, el terreno donde está el asentamiento y que habían proyectado adquirir, es parte del territorio ancestral de la comunidad indígena yukpa, cuyos miembros se han manifestado en contra de la ocupación por inconsulta y por estar ubicada en un sitio sagrado para ellas y ellos. Esta disputa se encuentra vigente desde 2016. Desde el inicio del proceso 
de preagrupación de guerrilleros(as) en la Serranía del Perijá hasta el día de hoy, el enredo ha sido cada vez mayor. Parte de los predios que están en el proyecto de vivienda y que son sitios sagrados yukpa se solapan con la zona de reserva forestal ${ }^{11}$ que señala la Ley $2^{\circ}$ de 1959 . Aun así, estos predios ya fueron incluidos en el Plan de Ordenamiento Territorial de Manaure (Cesar), lo que sobrepone figuras jurídicas que hacen cada vez más compleja la situación conflictiva entre comunidades ${ }^{12}$.

La mediación del Estado entre los excombatientes asentados en Tierra Grata y la comunidad yukpa parece solo empeorar la situación, al punto que en algún momento se planteó una toma del ETCR por parte de los indígenas ${ }^{13}$, sino se soluciona este tema.

\section{8. "No es agua potable". Entre la cooperación europea y la desatención estatal}

La Serranía del Perijá es la segunda fábrica de agua de la región Caribe, después de la Sierra Nevada de Santa Marta. Más de 10 ríos nacen allí y surten de agua a las poblaciones de la zona, a la vez que alimentan a los ríos Magdalena y Cesar. Esto contrasta con la situación que viven Tierra Grata y las comunidades vecinas, pues durante los primeros tres años del ETCR el acceso al líquido vital se hacía a través de dos carrotanques diarios, pagados por la Agencia de Reincorporación Nacional (ARN), por un costo de 830000 pesos colombianos, que equivalen a 242 dólares.

11 Las zonas de reserva forestal (ZRF) son áreas protegidas por el Estado, donde no se puede hacer tala de árboles o explotación de materias primas, por la importancia de los ecosistemas que allí se encuentran.

12 En las siguientes páginas se encuentra parte de la discusión que han mantenido indígenas y excombatientes al respecto de este conflicto: https://www.pacocol.org/ index.php/comites-regionales/cesar/10531-comunicado-comunidad-vereda-tierragrata-manaure-cesar; https://www.onic.org.co/comunicados-regionales/3550-respuesta-del-pueblo-yukpa-al-comunicado-de-la-comunidad-de-tierra-grata-de-lasfarc-titulado-nos-sentimos-perseguidos-por-la-dirigencia-yukpa

13 Véase "Yukpas se tomarían Tierra Grata”, en: https://elpilon.com.co/ yukpas-se-tomarian-tierra-grata/ 
Solo hasta finales de julio del 2019, luego de tres años de la llegada de los y las excombatientes, se comenzó a construir un acueducto pequeño que surte de agua no potable a Tierra Grata y a la comunidad de San José de Oriente. Nueve kilómetros recorren las mangueras de 3 pulgadas, desde la bocatoma en el Alto de la Virgen hasta las dos comunidades.

En Pondores la situación es mucho más grave, pues el departamento de La Guajira enfrenta serias afectaciones a sus acuíferos por la minería de carbón. Teniendo en cuenta que es un territorio seco y desértico que ha sufrido la desviación y muerte de ríos, y las sequías prolongadas como parte del impacto del cambio climático, la captación de aguas es un problema generalizado. A pesar de esto, Pondores ha tenido agua, aunque no potable, a través de un sistema de mangueras que los y las excombatientes han construido para abastecerse.

Estas estrategias les han permitido, en medio de muchas dificultades, contar con agua, la cual captan directamente de un caño del río Ranchería cercano al antiguo ETCR. No obstante, son conscientes de los impactos sobre el territorio y de sus pocas opciones, mientras ven cómo la escasez los cerca:

Puros caños secos y por allá donde captan el agua eso es, donde hay un nacimiento por ejemplo aquí, ya no le caben las mangueras a coger el poquito de agua. Allá no se desperdicia una gota de agua, o sea se seca el caño de ahí para abajo. (Rubiela, comunicación personal, 12 de julio de 2019).

El recorrido anterior por los territorios permite tener una imagen de las duras condiciones materiales en las cuales se está reproduciendo la vida en Pondores y Tierra Grata. En este panorama saltan a la vista problemáticas profundas que no solo muestran una fotografía de la situación que tanto allí como en los otros antiguos ETCR del país se vive, sino que desvela las condiciones de dificultad y carencia que constriñen a gran parte de la sociedad rural colombiana. 
El problema de la tenencia y uso de la tierra, como un asunto histórico que dio origen a la confrontación armada guerrillera; la falta de acceso a una vivienda digna, con agua potable; y la posibilidad de autodeterminación de las formas para reproducir la vida colectiva, se muestran aquí como elementos que configuran el tránsito de las y los excombatientes a la vida civil.

\section{Producir común para reproducir la vida}

Habitar un territorio es configurar un orden de interdependencia, de conexiones que permitan que la vida sea posible, aunque, paradójicamente, en algunos casos, adverso a ella. Este orden es dinámico, complejo y está mediado por las tradiciones o herencias que traen consigo quienes se encuentren en tal cometido, así como por las condiciones bióticas que imponen el lugar y las dinámicas socioculturales que lo atraviesan. El patriarcado, el colonialismo y el capitalismo hacen parte de ese legado que, sobre todo, la modernidad ha dejado a su paso. No obstante, la impugnación y el antagonismo frente a estos procesos violentos se mantiene y actualiza con antiguas memorias y nuevas estrategias creativas de las que "echan mano" (se sujetan), mujeres y hombres para producir tramas comunitarias.

Es así como el acervo de prácticas y sentidos con los que se enfrenta la necesidad vívida de generar redes que puedan soportar la existencia, muestran caminos múltiples de lucha con divergencias y coincidencias.

El ser humano, tal como nos recuerda Bolívar Echeverría, está “condenado" a crear, reinventar, actualizar, modificar o ratificar permanentemente la figura concreta de su socialidad comunitaria. Pues para el "ser humano" -que de entrada no puede pensarse como "individuo" aislado, sino como colectividad dinámica históricamente situada-, reproducirse, producir y consumir la forma de su condición comunitaria de existencia, no equivale a repetirla o reiterarla automáticamente, sino a crearla y reinventarla 
constantemente, a través de un proceso -permanente y "en marcha"- de codificación del conjunto de relaciones que se entablan entre los miembros de tal colectividad dinámica. (Gutiérrez et al., 2016, p. 280).

Las historias campesinas, indígenas, afrodescendientes, rurales y urbanas han mostrado en Colombia, Latinoamérica y el mundo la capacidad que tienen los pueblos y comunidades para organizar sus territorios, buscando que el acceso a los bienes comunes sea para la gran mayoría, a pesar de los violentos intentos por destruir las memorias y saberes que han habitado el continente de forma milenaria, y a pesar de las huellas dolorosas de autodesconocimiento, culpa e incluso desprecio que han dejados los continuos procesos de colonización. La conexión de nuestros pasados y la re-creación de los presentes mantienen un lazo, como una luz que alumbra la fuerza de otros mundos posibles ${ }^{14}$.

Estructuras como los Cabildos Indígenas, que se conservan hasta ahora; los Consejos Comunitarios afro; y las zonas de reserva campesina (ZRC), dan muestra de cómo, en Colombia, las comunidades han buscado estrategias de distribución para garantizar el acceso a tierra, agua, bosques, pastizales, entre otros. Cada uno con sus dificultades y contradicciones han desplegado capacidades colectivas para procurarse la vida y tejer vínculos comunitarios aun en medio de la guerra, ya que con una historia plagada de levantamientos civiles y el conflicto armado más largo de la región, vida y muerte se enmarañan continuamente.

Las estrategias para hacer frente a las amenazas constantes sobre las formas colectivas y comunitarias que no encajan plenamente con las lógicas patriarcales, coloniales y capitalistas han sido heterogéneas. Es decir, las luchas de las tramas comunitarias que amenazan el capital y su expansión han caminado distintos senderos. La gestión comunitaria

14 Otros mundos es una apuesta política que los zapatistas lanzan en México desde enero de 1994. 
de la vida en medio de la guerra se ha decantado por vertientes que van de lo reconocido por ley, como las mencionadas anteriormente, hasta la lucha armada, como es el caso de las guerrillas.

La visión de "tierra sin patronos" y "tierra para quien la trabaje"15, que ha sido y fue una de las primeras reivindicaciones que desde la Asociación Nacional de Usuarios Campesinos (ANUC), se enarboló contra latifundistas y terratenientes, así como la lucha por una reforma agraria integral, siguen siendo el motor, por lo menos en términos ideológicos, de estos procesos.

Existe, entonces, un horizonte interior compartido en las luchas que desde el campo se despliegan:

Horizonte interior de una lucha como aquel conjunto de aspiraciones y anhelos, no siempre lógicamente coherente entre sí, que animan el despliegue de una lucha colectiva en un momento particular de la historia y se expresa a través de ella. (Gutiérrez Aguilar, 2015. p 17).

La guerrilla de las FARC-EP, como expresión de la organización rural y, para el caso, campesina ${ }^{16}$, también generó modos de existencia. Allí se cultivaron estrategias para mantener la vida en las adversas condiciones que impone la guerra. Garantizar la alimentación diaria de las tropas, cuidar lo mejor posible de la salud, formar bajo sus propios

15 Estas dos frases hacen parte de los objetivos que se trazó la ANUC durante los setentas, plasmada en documentos oficiales de la organización campesina. Al respecto, véase: El poder político en Colombia, de Fernando Guillén; y el documento del CNMH Campesinos de Tierra y Agua: Campesinado en el departamento del Cesar, en este último se lee: "Se recuerda que la ANUC en La Guajira encontró respaldo y orientación en la Plataforma Ideológica (ANUC, 971), con uno de sus ejemplares en mano se destacó la siguiente frase: "Era un documento de orientación de la lucha campesina, alli quedó el objetivo de la organización que tanto recordamos: "'tierra para quien la trabaja" (Guillén Martínez, 2015).

16 Quintín Lame fue la única guerrilla indígena en Colombia. Se formó en el 1984 y terminó con el proceso de paz de 1990, junto al M-19. 
parámetros a su comunidad, y en general establecer el control sobre las condiciones de sobrevivencia en la medida de lo posible - pues la vida pende siempre de un hilo ante la posibilidad de un bombardeo-, implica prácticas, estrategias, capacidades, haceres que en todo caso constituyeron una propia forma social. En palabras de una excombatiente: "éramos una sociedad distinta".

Ese horizonte interior se aviva hoy en los antiguos ETCR abrevando de los aprendizajes de ambas tradiciones de lucha. Comenzar a tramar comunidad en cada uno de los territorios, sin armas, con los saberes que se han cultivado a lo largo del tiempo, es parte de lo que actualmente está pasando en estos espacios. La pericia con que se ponen en juego las tradiciones de lucha como las Juntas de Acción Comunal (JAC), las convivencias guerrilleras, las asociaciones y cooperativas, entre otras, están configurando nuevos territorios.

La diversidad de quienes llegaron a estos espacios es el reflejo de una región y un país plural y empobrecido. Personas indígenas, afrodescendientes, campesinas, citadinas, ingresaron a las filas guerrilleras, la mayoría muy jóvenes: entre los 14 y 16 años. Sus historias en el campo o la ciudad narran las violencias que cercan a gran parte de las y los colombianos.

Cuando llegaron los paramilitares. La familia mía fue amenazada y yo decidí irme con la guerrilla (...). A veces no estudiamos porque no había cómo pagarles a los profesores, siempre eran tres meses y ya. Nosotros nos criamos fue trabajando en el campo. (Yeimi, comunicación personal, 17 de julio de 2019).

Siendo cierto que es el campo donde la guerra ha sido más cruel y directa, es imposible negar que cada ciclo de violencia se haya expandido hasta llegar a cada rincón del país. En este sentido, quienes no hacemos parte de la capa más alta de la pirámide social que impone el capitalismo, hemos sido alcanzados por la guerra; claro está, de forma 
diferenciada según el lugar, la condición económica y social, el sexo y la preferencia sexual. Es por esto que, como bien lo exponen Gutiérrez y Palley, es necesario:

Entender que la guerra desatada es directamente en contra nuestra: de la población trabajadora, de las mujeres y varones que una y otra vez, más allá de la precariedad que el capitalismo contemporáneo impone a la vida individual de cada portador de "fuerza de trabajo", somos capaces de relanzar nuestra propia energía para crear con otras y otros, ámbitos de resistencia y lucha, donde cultivamos otras capacidades de nuestra calidad humana jamás aplastadas del todo por el capital y su voracidad. (2016, p. 5).

Avanzar en la construcción de un nuevo espacio de vida en comunidad es una posibilidad inédita para crear nuevos caminos que apunten a dignificar la vida. Sin embargo, no se puede soslayar que en ella es donde también se generan e incuban las opresiones y violencias a las que estamos expuestas las mujeres. No se trata, pues, de defender a ultranza y en cualquier circunstancia una "comunidad ideal", sino de asumir los procesos en su complejidad.

Cuando estábamos en las FARC todo estaba reglamentado porque nosotros éramos militares, cierto, y nadie hacía lo que se le daba la gana, eso sí, está claro que de allí se cumplía porque se cumplía una orden. Ahorita estamos acá y este proceso es muy de conciencia, pero ya es muy difícil, uno se da cuenta que la gente es motivada por las órdenes, por la parte que lo obliguen. Que no debiera de ser así, en lo militar porque era lo militar. Pero uno encuentra ahorita de que mucha gente como que se la absorbe el medio ambiente y es un medioambiente que no es el ambiente más sano. (Rubiela, comunicación personal, 12 de julio de 2019).

Asentarse en un territorio ha implicado para las y los excombatientes el encuentro con formas organizativas y dinámicas distintas a las que se daban en la guerrilla. Así mismo, la llegada de sus familias les abrió 
una oportunidad para recomponer los vínculos de parentesco, irrumpiendo en los esquemas militares de su antigua vida. Esta diversidad de sujetos que se encuentran y comparten los territorios viene dando forma, no sin tensiones, a sociabilidades particulares e inéditas.

En este caminar, en los ETCR las y los excombatiente no han estado solas y solos. Plantarse en un lugar lleva necesariamente, como ya se dijo, a estar con otros y otras. La llegada a los espacios de reincorporación, en principio, les significó encontrarse con los habitantes de las veredas y corregimientos cercanos, los cuales ya tenían unas formas de estar allí; más adelante, llegaron sus propias familias y con ello la oportunidad de recomponer los vínculos familiares y sociales, así como la posibilidad de establecer un hogar con personas ajenas a la organización.

Y esos "varios" que conforman el agrupamiento específico que posee, puede ser multiforme y enormemente heterogéneo, aunque en todo caso tienen en común, en tanto coparticipación en una calidad o circunstancia, el hecho de estar situados espacial y temporalmente. Es decir, los hombres y mujeres que comparten lo común conforman colectividades particulares y específicas que establecen, además, normas específicas para usufructuar y para transmitir tales derechos a las generaciones siguientes. (Gutiérrez Aguilar, 2015, p. 15).

\section{Producir sentidos colectivos}

Las mujeres excombatientes buscan producir las condiciones necesarias para reproducir la vida, una que sea digna de ser vivida y que parta del arraigo y trabajo en la tierra, esa que les ha sido esquiva durante tanto tiempo. Para ellas, los ETCR se presentaron como una posibilidad para aportar en la construcción de una sociedad más justa, esta vez sin armas. Aun así, existe un laberinto burocrático en el que se encuentran atrapados los sueños y proyectos de las excombatientes, quienes buscan volver a su tradición campesina. La falta de tierras para desarrollar 
sus proyectos sigue siendo el problema central para lograr una reincorporación digna.

Sin embargo, las farianas siguen apostando por crear estrategias para reproducir la vida colectiva desde los territorios. Como parte de las estrategias desplegadas se encuentran los Comités de Mujer, Género y Diversidad (en adelante Comités). Estos Comités son espacios organizativos, que se desprenden de la Comisión Mujer, Género y Diversidad del Partido FARC (ahora renombrado Comunes), a nivel nacional, y tienen dinámicas particulares en cada territorio. Desde allí las mujeres excombatientes han venido trabajando en la construcción de varios proyectos que esperan pronto sean productivos.

En ambos espacios, Pondores y Tierra Grata, se avanza en la creación de viveros. Desde ellos las mujeres buscan no solo desarrollar un proyecto productivo sostenible y amigable con el ecosistema, sino un lugar para trabajar en conjunto con las comunidades aledañas a los antiguos ETCR.

En Pondores este proyecto se encuentra avanzado, a pesar de la lentitud de los trámites burocráticos que les impone la cooperación internacional. Dama Verde es el nombre que le han puesto las excombatientes a esta iniciativa productiva agroecológica que se viene desarrollando en los predios arrendados por la comunidad del antiguo ETCR en la vereda de San Luis, ubicada a unos 15 minutos del espacio.

A través del Programa de las Naciones Unidas para el Desarrollo se han entregado 80 millones de pesos, unos 20900 dólares, para alquiler de maquinaria, limpieza del terreno, y adquirir mangueras, herramientas, alambre y postes para cerca. Una hectárea y media es el espacio con el que cuentan para desarrollar el vivero; en él las plantas medicinales, y los árboles y arbustos para la restauración de fuentes hídricas serán los productos insignia. Así mismo, esperan producir abono y fertilizantes agroecológicos para los cultivos de la zona. 
Este espacio ha permitido no solo el trabajo entre mujeres, sino un encuentro más íntimo entre ellas, ya que en las jornadas diarias también se habla de las cosas que las afectan en su vida cotidiana. Allí se aborda el tema del cuidado y la reproducción de la vida en colectivo, en las familias, y se comparten estrategias para evitar que estas responsabilidades vuelvan a recaer de forma exclusiva en las mujeres. Es un tiempo de remembranzas de su vida guerrillera y de proyección en su vida civil. En el vivero se siguen re-produciendo las estrategias de cuidado colectivo, sobre todo en relación con los niños y niñas que las acompañan.

El tema de la maternidad ha sido complejo a la hora de mantener la participación política de las mujeres en los antiguos ETCR. Las condiciones de la guerra impidieron que muchas de ellas pudieran hacer el proceso de crianza, el cual ahora aparece como un anhelo por cumplir. Sin embargo, su deseo de vivir la maternidad no es lo que esperaban. El encierro, la inexperiencia, el trabajo duro y constante que implica el cuidado de un bebé y la alimentación diaria de la familia, la construcción del vínculo materno con hijos criados por otras personas y su resistencia a delegar los cuidados de los más pequeños a la hermana mayor, como es común en el campo, son experiencias totalmente nuevas para ellas.

Este deseo de crianza es algo que las mujeres farianas una y otra vez pondrán de manifiesto, en ambos territorios. Al igual que las contradicciones que les genera el ejercicio de su maternidad vinculada al encierro y la responsabilidad de la reproducción de los cuerpos de quienes conviven con ellas. El cambio de una vida organizada según los tiempos y necesidades de la guerra, donde todos los aspectos de la vida están reglados, a una cotidianidad donde deben construir sus propias normas y modos de relacionarse, encontrar y poner límites, ciertamente, es algo que les genera tensiones, a la vez que les despierta interrogantes sobre qué hacer y cómo re-organizar la vida. 
La visión de algunas madres que están intentando dar un orden a su tiempo, distribuyendo las labores del hogar y la crianza con sus compañeros, apoyándose en otros y otras, o de quienes han decidido no tener hijos por ahora, es que la maternidad es un problema para el desarrollo político de las mujeres.

Ha habido impacto aquí, sí ha habido negativo, digámoslo, en el sentido de que, por lo menos, mire, ahorita que yo me fui a trabajar habiamos poquitas mujeres trabajando, no habiamos sino tres. Porque uno va a buscar las compañeras y la que no está embarazada tiene el bebé todavía de cuidados, antes de los seis meses, o simplemente tiene los seis meses pero, por ejemplo, el espacio que tenemos aquí de cuidado solo le brinda un cuidado de medio tiempo y a medio día no hay quien reciba el niño, (...) eso sí ha faltado acá, si tenemos ese problema, entonces las mujeres se amarran mucho. (Rubiela, comunicación personal, 12 de julio de 2019).

Por eso intentan desde los espacios del Comité y otros como comunicación, vincular a las mujeres a los procesos políticos organizativos. Sin embargo, esto tiende a cargar de responsabilidades a las mujeres, sin lograr generar un cambio en la gestión de los trabajos domésticos y de crianza.

Con todo y esto, las mujeres farianas exhiben rebeldías cotidianas contra los mandatos de encierro, individualización y dependencia económica, así como frente a las características asignadas a las mujeres como sumisas, serviciales, cuidadoras, dispuestas y disponibles.

El interés y la participación en procesos educativos técnicos y profesionales; productivos como la ganadería, la agricultura y la confección; y políticos en las mesas de género, con candidaturas electorales locales y comités de comunicación, entre otros, revelan su deseo de seguir transformando estos mandatos. Todo esto a pesar de los cercos a los cuales intentan hacer frente desde los lazos de confianza que se han tejido en la guerra; así, el cuidado de los niños y niñas puede ser asumido por 
una o varias personas si la madre debe salir o realizar algún trabajo. Mantener y expandir estas formas de cuidado es un reto frente a la individualización progresiva que enfrentan en la inserción a la vida civil.

El carácter de las mujeres farianas continuamente se revela como subversivo. Dentro de las historias que tuve la oportunidad de escuchar de su propia voz, veo cómo el dolor se transforma en rebeldía. El ingreso a las filas, para muchas, fue una fuga de la familia y su orden patriarcal, de la sociedad y sus lógicas de despojo. En sus relatos no son las víctimas, como se les ha querido presentar desde los discursos oficiales. En sus palabras, son las revolucionarias, las que luchan por una transformación social no solo para volver a la tierra, cuidarla y trabajarla, sino para cambiar el lugar de las mujeres en la sociedad, para romper con la dominación de los varones y del régimen patriarcal.

El que sean sujetas políticas incomoda a la sociedad y esto no excluye a sus compañeros o camaradas. Los esfuerzos de las farianas, por no perder su proyecto político como mujeres revolucionarias, de dirigen a romper los límites que el Estado, el partido y los discursos sobre género les pretenden imponer. Ellas no quieren ser un sector dentro de la sociedad, quieren salir con sus propuestas al encuentro con nuevas ideas y visiones, contribuir al avivamiento de viejas intuiciones con la potencia transformadora de las mujeres, desordenando las lógicas patriarcales en los territorios.

Durante el tiempo en filas, hablar de género refería solo a las diversidades sexuales. Es importante señalar que para las FARC-EP era anormal todo lo que no correspondiera a la norma heterosexual. Algunas farianas, de hecho, señalan: "No queríamos que eso entrara al grupo, porque decíamos que se nos iba a dañar la organización, o sea, se nos iba a contaminar". El género era "temas de gente vaga". Otro sentido común frente al género, es que este es "un tema de mujeres". 
En cuanto al feminismo, se repite una y otra vez que hay un feminismo que odia a los hombres, los excluye y no sirve para pensar en una organización mixta ni en un mundo habitado por mujeres y hombres. Por el contrario, el feminismo insurgente es una propuesta para una sociedad pensada desde lo mixto, por eso dentro de sus postulados se encuentra el trabajo con nuevas masculinidades o masculinidades no violentas.

Aunque existen prevenciones, esto no ha impedido que las excombatientes se relacionen y participen en espacios donde confluyen mujeres feministas o no, como el Encuentro de Organizaciones de Mujeres del Caribe, la Instancia Especial de Género para la Paz o los encuentros de mujeres campesinas. La cercanía de las historias vividas en la guerra ha generado lazos que traspasan los relatos hegemónicos de buenos y malos, abriendo caminos en perspectiva de una vida digna donde la diferencia no sea una sentencia de muerte. Así, las mujeres que han estado desde distintos lugares afrontando la guerra se encuentran para buscar cómo vivir juntas, aun en medio de la reconfiguración de la guerra y las violencias.

\section{El feminismo insurgente, una apuesta de paz de las mujeres excombatientes}

"Nosotras vinimos por todo, queremos la paz, la libertad, la justicia y la alegría" (Mujer fariana, 2018).

El feminismo insurgente es una propuesta que surgió del encuentro entre mujeres en La Habana, Cuba. Es una apuesta de las mujeres farianas por construir una forma propia de reconocer su experiencia como guerrilleras, de nombrarse a sí mismas como sujetas políticas y de construir sentidos feministas partiendo de una reinterpretación de su papel dentro de la insurgencia. Nació de sus experiencias cotidianas como revolucionarias en armas, se sigue construyendo de forma colectiva con las nuevas integrantes urbanas y civiles que llegan al Partido FARC y apunta a la transformación de "los mandatos sociales propios del patriarcado" (Mujer Fariana, 2018). 
El proceso de paz fue el escenario de alianzas insólitas entre mujeres de muy diversos procesos. Allí confluyeron farianas, feministas, excombatientes de distintas latitudes, participantes en procesos de mujeres, técnicas en temas de género y lideresas colombianas, todas ellas con un horizonte definido: el fin de la guerra. Esta fue una oportunidad única para que las mujeres insurgentes hablaran de sus experiencias de vida en la guerra, más allá del lugar de la víctima que históricamente se les ha asignado. Fue un espacio de reflexión y puesta en común de las potencias que todas, desde distintos lugares, despliegan y alimentan más acá, contra y más allá (Holloway, 2011) de la triada patriarcado-colonialismo-capitalismo.

La vivencia de la guerra desde la organización armada y las transformaciones que implica para las mujeres la dejación de armas, vista desde excombatientes de otros procesos guerrilleros resonó y ayudó a reconocer los límites de la "igualdad” construida dentro de las FARC-EP. Para las farianas este fue un momento inédito pues:

Nunca antes las mujeres guerrilleras y exguerrilleras habian podido hablar de feminismo como se ha podido hacer en este proceso de paz. Tenemos muchas cosas por decir y muchas otras por hacer. (Mujer Fariana, 2018).

Ese dialogó desde una perspectiva feminista les despertó inquietudes sobre los límites y las posibilidades que se les abrirían tras el proceso de paz. Sin embargo, lo que se recogía de las experiencias de las mujeres excombatientes fue:

Ese mismo común denominador, mientras estaban en la guerrilla los hombres veían a las mujeres con mucha admiración y parte del proceso, pero cuando se sale a la vida civil, pues quedan confinadas a la casa. (Olga, comunicación personal, 23 de junio de 2019). 
Conociendo esta realidad, las excombatientes se proponen no seguir el trazo de ruta que impone el orden patriarcal, reinterpretando su experiencia "a la luz de diferentes corrientes de pensamiento feministas y del desarrollo propio” de su visión fariana, como propone el feminismo insurgente.

El feminismo insurgente es entonces una apuesta emancipatoria que dialoga con otros saberes y apuestas feministas; es una iniciativa colectiva para aportar a la transformación de los mandatos sociales propios del patriarcado y del capitalismo como sistemas de opresión y de poder, desde nuestros saberes y vivencias como mujeres farianas. (Mujer Fariana, 2018).

Para las farianas, a pesar de que el feminismo insurgente tiene una base marxista, sienten la necesidad de complementar esta visión con otros feminismos. Retoman así elementos de los feminismos populares, comunitarios, campesinos y decoloniales para dar forma a su propuesta, planteando:

Despatriarcalizar la sociedad y todo lugar donde hagamos trabajo político y organizativo. Esto consiste en defender los derechos de las mujeres, aportar en la construcción de masculinidades no violentas, reconocer las diversidades sexuales, transformar las relaciones de desigualdad que sostenemos en nuestra cotidianidad, pero también aquellas violencias estructurales (Mujer Fariana, 2018).

Entender la teoría feminista desde sus vivencias como guerrilleras, aunque ha sido un proceso complejo que implicó movimientos fuertes al interior de su organización y de ellas mismas, les ha permitido encontrar en su experiencia práctica elementos que rompen con el par ordenador femenino-masculino. Las sobrevivencias en la guerra implicaron establecer ejercicios de paridad en las actividades básicas para la reproducción de la vida diaria, que históricamente han asignado a las mujeres labores como cocinar, procurar el espacio donde se habita y, en fin, ser una persona funcional que se hace cargo de sí misma. Sin embargo, también lograron ver los límites de su "igualdad”, los techos de cristal en las estructuras de decisión y poder - relacionados con 
el mantenimiento del imaginario de que los hombres toman mejores decisiones y tienes mayores capacidades para liderar la política y la guerra- y repensar los términos en que buscan relacionarse tras la dejación de las armas.

En este sentido, existe una apuesta por mantener y ampliar los logros materiales en cuanto a la paridad de los trabajos de reproducción de la vida individual y colectiva, a la vez que se impulsa la construcción de un orden simbólico propio. Reconstruir su genealogía dentro de la guerrilla y afianzar sus linajes de lucha, así como "fortalecer las capacidades de las mujeres como sujetas políticas de derechos, en la participación política, en la toma de decisiones" (Mujer Fariana, 2018) son las estrategias que se han trazado en este camino.

La inserción a la sociedad mayoritaria confronta a las farianas con un posible retroceso en su autonomía material, con la tendencia a profundizar las diferencias jerárquicas dentro de su organización, bien sea porque en la sociedad mayoritaria persiste la división sexual del trabajo o por las diferencias económicas que se dan en este proceso de reorganización. En relación con este último punto, no se pueden pasar por alto las condiciones desiguales que enfrentan las excombatientes que permanecen en los ETCR y su dependencia económica de lo pactado en la reincorporación, frente a aquellas que viven en la ciudad y tienen empleos en los mecanismos de implementación del Acuerdo de Paz o dentro del partido. Tampoco se puede olvidar que los antiguos comandantes varones son quienes mayoritariamente gozan de los privilegios que ofrece ser dirigente del partido, con el financiamiento correspondiente.

En todo caso, sigue existiendo una base común de las mujeres excombatientes, que desde la experiencia les permite seguir articulando estrategias de lucha dentro y fuera de su organización. En este sentido, el feminismo insurgente se presenta como una propuesta subversiva 
del orden patriarcal, donde se busca cultivar espacios entre mujeres, reconocer las diversidades sexuales y construir junto con los hombres masculinidades no violentas que recuperen las prácticas paritarias que se dieron en la lucha armada.

El feminismo insurgente de las farianas sigue el camino de romper la jerarquización de las luchas, donde las prioridades abarcativas clausuran la posibilidad de una revolución en la vida cotidiana. Habilitar la pregunta por la transformación desde la reproducción de la vida colectiva, aún desde su perspectiva partidista, busca abrir fisuras para ensayar en los territorios otras formas de construir entre varones y mujeres.

Así termina este corto recorrido por los ETCR de Pondores y Tierra Grata, donde las mujeres excombatientes de las FARC nos muestran la forma en que están construyendo territorios; su lucha por garantizar las condiciones mínimas para la existencia que se despliega en la vida cotidiana produciendo común y reproduciendo la vida, donde su creatividad se despliega y prefigura el tan anhelado sueño de la paz. Este empeño, sin embargo, no es solo de las mujeres excombatientes ni de sus compañeros, es un horizonte de lucha compartido con gran parte de la sociedad colombiana. Muestra de ello es el estallido popular-comunitario que actualmente (desde el 28 de abril del 2021) defiende en las calles la utopía de una sociedad distinta.

\section{Referencias}

Agencia Nacional de Minería. (s.f.). Regalías y contraprestaciones económicas. Recuperado de https://www.anm.gov. $\mathrm{co} / ? \mathrm{q}=$ regalias-contraprestaciones-economicas

Aponte, Andrés Felipe. (2019). Grupos armados y construcción de orden social en la esquina sur del Tolima, 1948-2016. Bogotá: Centro de Investigación y Educación Popular. 
Campo Palacios, Daniel. (2018). Territorios, control y diferencia étnica: Comunidades negras e indígenas frente al despojo en el norte del Cauca (Primera ed). Popayán: Editorial Universidad del Cauca.

Centro Nacional de Memoria Histórica [CNMH]. (2011). Mujeres y guerra. Víctimas y resistentes en el Caribe colombiano (Primera ed.). Bogotá: Taurus.

Centro Nacional de Memoria Histórica. (2017). Campesinos de tierra y agua. Memorias sobre sujeto colectivo, trayectoria organizativa, daño y expectativas de reparación en la región Caribe 1960-2015. Campesinado en el departamento del Cesar. Bogotá: Centro Nacional de Memoria Histórica.

Comisión Colombiana de Juristas. (31 de octubre de 2011). La política agraria y los derechos de las mujeres en Colombia. Recuperado de https://www.coljuristas.org/documentos/libros_e_informes/la_politica_agraria_y_los_derechos_de_las_mujeres.pdf

Comisión Mujer, Género y Diversidad, Farc. (Enero de 2020). Estrategia integral para la reincorporación de las mujeres de las FARC. Recuperado de https://partidofarc.com.co/farc/wp-content/uploads/2020/04/Estrategiaintegral-para-la-reincorporacio \% CC \% 81n-de-mujeres-de-FARC.pdf

Congreso de la República. Ley 2 de 1959. Sobre economía forestal de la nación y conservación de recursos naturales renovables. Enero 17 de 1959. DO N. ${ }^{\circ} 29.861$.

Deere, Carmen Diana y León, Magdalena. (2005). La brecha de género en la propiedad de la tierra en América Latina. Estudios Sociológicos, 23(68), 397-439. Recuperado de https://miradascriticasdelterritoriodesdeelfeminismo.files.wordpress.com/ 2013/07/brecha-genero-tierra.pdf

Defensoría del Pueblo. (2014). Crisis humanitaria en La Guajira 2014. Acción integral de la Defensoría del Pueblo en el departamento. Recuperado de https://www.defensoria.gov.co/public/pdf/informedefensorialguajira11.pdf

Departamento Administrativo Nacional de Estadística [DANE]. (2016). Tercer Censo Nacional Agropecuario. Recuperado de https://www.dane.gov.co/files/images/foros/foro-de-entrega-de-resultados-y-cierre-3-censo-nacionalagropecuario/CNATomo2-Resultados.pdf 
Fajardo M, Dario. (2015). Estudio sobre los orígenes del conflicto armado, razones de su persistencia y sus efectos más profundos en el sociedad colombiana. Bogotá: Espacio crítico. Recuperado de https://www.corteidh. or.cr/tablas/r33442.pdf

Fals Borda, Orlando. (2008). La subversión en Colombia: el cambio social en la historia. Bogotá: Fundación para la Investigación y la Cultura: Centro Estratégico de Pensamiento Alternativo.

Forero Lloreda, Eduardo; Mattos Orozco, Ronald y Amador Arévalo, Arturo. (2017). La Guajira como territorio de "Espacios Basura”. Una mirada a la Economía de la subsistencia. Letras Verdes. Revista Latinoamericana de Estudios Socioambientales, (22), 315-333.

Forjando Paz. (2017). Ruta para la construcción de una paz estable y duradera: Acuerdo de paz definitivo entre el Gobierno Nacional y las Farc-EP, 24 de noviembre de 2016.

Fuerza Alternativa Revolucionaria del Común [FARC]. (2017). Tesis de feminismo, mujer y género para el congreso constitutivo del Nuevo Partido. Recuperado de https://partidofarc.com.co/farc/2018/11/21/tesis-de-feminismomujer-y-genero-para-el-congreso-constitutivo-del-nuevo-partido/

Gobierno Nacional y Farc-EP. (2016). Acuerdo final para la terminación del conflicto y la construcción de una paz estable y duradera. Recuperado de https://www.jep.gov.co/Documents/Acuerdo \%20Final/Acuerdo \%20 Final\%20Firmado.pdf

Guillén Martínez, Fernando. (2015). El poder político en Colombia. Bogotá: Editorial Planeta.

Gutiérrez Aguilar, Raquel. (2015). Horizonte comunitario-popular. Antagonismo y producción de lo común en América Latina. Puebla: Benemérita Universidad Autónoma de Puebla, Instituto de Ciencias Sociales y Humanidades "Alfonso Vélez Pliego".

Gutiérrez Aguilar, Raquel y Paley, Dawn. (2016). La transformación sustancial de la guerra y la violencia contra las mujeres en México. DEP. Deportate, esuli, profugbe. Rivista telematica di studi sulla memoria femminile, (30), $1-13$. 
Gutiérrez Aguilar, Raquel; Linsalata, Lucía y Navarro, Mina Lorena. (2016). Repensar lo político, pensar lo común: claves para la discusión. En Daniel Inclán, Lucía Linsalata y Márgara Millán (Coords.), Modernidades alternativas. Ciudad de México: Universidad Nacional Autónoma de México.

Haraway, Donna y Bras Harriott, Sofía. (2014). Manifiesto para cyborgs: ciencia, tecnología y feminismo socialista a finales del siglo XX. Mar del Plata: Puente Aéreo.

Holloway, John (2011). Agrietar el capitalismo. El hacer contra el trabajo (Trad. Francisco T. Sobrino). Buenos Aires: Ediciones Herramienta.

Instituto Kroc de Estudios Internacionales para la Paz. (2019). Actualización. Informe 3 del Instituto Kroc. Hacía una paz de calidad en Colombia. Recuperado de https://kroc.nd.edu/assets/315919/190408_actualizacio_n_informe_3_instituto_kroc_feb19.pdf

Lamus Canavate, Doris. (2010). De la subversión a la inclusión: movimientos de mujeres de la segunda ola en Colombia, 1975-2005. Bogotá: Instituto Colombiano de Antropología e Historia.

Legrand, Catherine. (2016). Colonización y protesta campesina en Colombia: 1850-1950. Bogotá: Universidad Nacional de Colombia.

León, M. (2011). La desigualdad de género en la propiedad de la tierra en América Latina. En C Verschuur (Ed.)Du grain à moudre (pp. 189-207). Graduate Institute Publications. https://doi.org/10.4000/books.iheid.6756

Navarro, Mina. (2015). Luchas por lo común: antagonismo social contra el despojo capitalista de los bienes naturales en México. México: Bajo Tierra Ediciones.

Observatorio de Conflictos Ambientales [OCA] e Instituto de Estudios Ambientales [IDEA] Universidad Nacional de Colombia. (27 de febrero de 2017). Minería de carbón - Drumond - Prodeco - Murray Energy - Cesar. Análisis Dinámica de Actores y Acciones. Recuperado de https://conflictos-ambientales.net/oca_bd/media_references/view/1564. https://conflictos-ambientales.net/oca_bd/env_problems/view/4

Oxford Committee for Famine Relief [OxFAM]. (30 de agosto de 2017). Radiografía de la desigualdad. Lo que nos dice el último censo agropecuario 
sobre la distribución de la tierra en Colombia. Recuperado de https:// www-cdn.oxfam.org/s3fs-public/file_attachments/radiografia_de_la_desigualdad.pdf

Pensamiento y Acción Social [PAS] y Arbeitsgruppe Schweiz Kolumbien [ASK]. (2015). Informe sombra de sostenibilidad de las operaciones de Glencore en Colombia. Recuperado de https://www.academia.edu/39240038/INFORME_SOMBRA_DE_SOSTENIBILIDAD_DE_LAS_OPERACIONES_DE_ GLENCORE_EN_COLOMBIA

Sandoval Acosta, Girlandrey; Cardoza, Laura y Correal Cabezas, Ximena. (Junio de 2018). Feminismo insurgente. Una apuesta fariana de paz. Bogotá: Programa de las Naciones Unidas para el Desarrollo y Embajada de Noruega. Recuperado de http://www.mujerfariana.org/vision/1060-feminismoinsurgente-una-apuesta-fariana-de-paz.html

Secretaría Técnica del Componente Internacional de Verificación CINEP/PPPCERAC. (Febrero de 2019). Quinto informe de verificación de la implementación del Acuerdo Final de Paz en Colombia para los Verificadores Internacionales Felipe González y José Mujica (A.F. 6.3.2). Recuperado de https:// www.cinep.org.co/Home2/component/k2/670-quinto-informe-de-verificacion-de-la-implementacion-del-acuerdo-final-de-paz-en-colombia-paralos-verificadores-internacionales.html

Segato, Rita Laura. (2018). Contrapedagogías de la crueldad. Buenos Aires: Prometeo Libros.

Vega Cantor, Renán. (2002). Gente muy rebelde: Protesta popular y modernización capitalista en Colombia (1909-1929). Bogotá: Ediciones Pensamiento Crítico. 